\title{
TOXIC ANTERIOR SEGMENT SYNDROME (TASS) WITH SEVERE PIGMENT DISPERSION
}

\author{
K. Stephen Sudhakar1, M. Loganathan², R. Panduragan³, C. Charanya4
}

\section{HOW TO CITE THIS ARTICLE:}

K. Stephen Sudhakar, M. Loganathan, R. Panduragan, C. Charanya. "Toxic Anterior Segment Syndrome (TASS) with Severe Pigment Dispersion". Journal of Evolution of Medical and Dental Sciences 2014; Vol. 3, Issue 46, September 22; Page: 11271-11278, DOI: 10.14260/jemds/2014/3469

\begin{abstract}
AIM: To clinically analyze the cases of TASS with severe pigment dispersion following uncomplicated cataract surgery in a tertiary care teaching hospital from January 2011 to January 2013. DESIGN: Retrospective case series study. MATERIALS AND METHODS: The records of all eyes developing TASS with severe pigment dispersion following uncomplicated Cataract surgery were retrospectively reviewed. Clinical outcomes including visual acuity, intraocular pressure and complications were recorded at $1^{\text {st }}$ post-operative day, $7^{\text {th }}$ post-operative day and after six weeks of follow up visits. RESULTS: TASS with severe pigment dis pension was recorded in five out of 1060 patients. All cases were females. Phacoemulsification with foldable IOL was done in 2 patients and Small Incision Cataract Surgery (SICS) with in bag posterior chamber IOL was done in three patients. All patients had pain which was less severe when compared to the amount of inflammation. Visual acuity ranged from 6/36 to perception of light. All the five patients had rim to rim corneal edema which was seen from the first post-operative day and persisted at six weeks follow up. Pupils were dilated and fixed in all patients. Intraocular pressure was raised in four out of five patients who poorly responded to medical treatment. Dense pigment clumps were seen in the corneal endothelium and on the surgical wound site after one week in three out of five patients and increased at 6 weeks of follow up. Visual acuity did not improve in any of the patient even with treatment. The reduced visual acuity was due to worsening corneal edema and dense pigment clumping in corneal endothelium. CONCLUSION: TASS with severe pigment dispersion has more complication than routine TASS. The complication are due to dense pigment clumping in cornea and angle of anterior chamber causing corneal endothelial de-compensation and raised Intraocular pressure, which persisted even after the inflammation subsided. Although the incidence is less it is potentially blinding condition therefore prevention of TASS is of primary importance.
\end{abstract}

KEYWORDS: Toxic anterior segment syndrome, pigment dispersion, corneal edema.

INTRODUCTION: Toxic Anterior Segment Syndrome (TASS) is acute, non-infectious, sterile inflammation affecting the anterior segment of eye ball. It is a complication of anterior segment surgery including cataract surgery with intraocular lens implantation. ${ }^{[1]}$

It occurs within 24 hours after surgery and is characterized by diffuse corneal edema that extends from limbus to limbus associated with severe photophobia, marked decreased vision and violent anterior chamber reaction. ${ }^{2]}$

TASS typically develops $12-24$ hours after surgery in contrast to acute infectious endophthalmitis which usually develops after 2-7 days.

TASS is often misdiagnosed as infectious endophthalmitis for which the treatment varies. 
Endophthalmitis is a bacterial or fungal infection affecting the Intraocular Cavities such as vitreous and or aqeous humour. Most cases are exogenous but some are endogenous arising from bacteremic or fungaemic seeding of Intraocular Structures..$^{[3]}$

Endophthalmitis caused by staphylococcus epidermitis and Bacillus cereus mimics TASS. Failure to recognize it can rapidly destroy the eye.[4]

The etiology of TASS could be multifactorial. Such as endotoxins contaminating Balanced Salt solutions, denatured viscoelastic, improper sterilization of tubing's and equipment's, preservatives in medication, metallic precipitates, topical drops and ointment entering the anterior chamber. ${ }^{[5,6]}$ Sterile Inflammation induced by intraocular lenses may also cause TASS.

It responds to steroid therapy but may result in permanent damage to trabecular meshwork resulting in irreversible rise in Intra ocular pressure. The main stay of treatment lies on prevention of TASS.[7]

Severe pigment dispersion in anterior segment and in surgical wound area is a very rare complication of TASS and is not much reported.

AIM: The Aim of the study is to retrospectively analyze the clinical characteristics of cases of Toxic Anterior Segment Syndrome (TASS) with severe pigment dispersion following uncomplicated cataract surgery and their management outcome in a tertiary care teaching hospital.

METHODS: A two year retrospective study was conducted on patients who underwent cataract surgery from January 2011 to January2013 and the post-operative patients of TASS with severe pigment dispersion following uncomplicated cataract surgery were clinically analyzed.

Inclusion Criteria: Postoperative patients of TASS associated with severe pigment dispersion in anterior segment.

\section{Exclusion Criteria:}

- Patients with TASS not associated with pigment dispersion.

- Patients with post-operative iridocyclitis not corresponding to TASS.

- Patients with endophthalmitis.

- Patients with complicated or traumatic cataract.

METHODOLOGY: All the eyes which developed TASS with severe pigment dispersion in uncomplicated cataract surgery were retrospectively reviewed. Clinical outcomes including anterior segment finding, fundus findings, visual acuity, intraocular pressure and complications were recorded at $1^{\text {stp }}$ post-operative day, $7^{\text {th }}$ post-operative day, and after 6 weeks of follow up visits and the results were analyzed.

RESULTS: Out of 1060 cataract surgeries performed five eyes of five patients showed the signs of TASS with severe pigment dispersion. Age of the patients ranged from $65-72$ years with an average age of 68.5 years. 
All the patients were females (100\%). Out of five patients, phacoemulsification $(2.8 \mathrm{~mm}$ scleral incision) with foldable IOL was done in two patients and small incision cataract surgery (SICS) with rigid poly methyl methacrylate IOL was done in three patients.

Type of Cataract: Two patients had dense posterior sub capsular cataract, two patients had immature cortical cataract, and one patient had grade four nuclear cataracts.

Symptoms: All the five patients $(100 \%)$ had pain which is less when compared to the amount of inflammation.

1stPost-Operative day (table 1): All patients had poor visual acuity ranging from 6/36 to perception of light with no improvement with pinhole.

\section{SIGNS:}

Cornea: Rim to Rim corneal edema with increased corneal thickness and corneal epithelial defects was present in all patients (100\%) (Figure 1).

Anterior Chamber: Fibrinous reaction was present in all patients with severe flare and cells (100\%) None of the patients had hypopyon in anterior chamber.

Pupils: Pupils were dilated, fixed not reacting to light in all 5 patients (100\%). Size of the pupils ranged from $(5 \mathrm{~mm}-8 \mathrm{~mm})$ with an average size of $(6.5 \mathrm{~mm})$. (Figure 2$)$.

IOL: In the bag posterior chamber IOL was present in all patients.

In SICS Patients: Two patients were implanted with three piece poly methyl methacrylate (PMMA) lenses and one patient was implanted with single piece rigid PMMA lens.

In phaco emulsification patient's one patient was implanted with foldable single piece hydrophilic acrylic lens and the other patients with three piece foldable hydrophilic acrylic lens.

Intraocular pressure was raised in four out of five patients (80\%) (Measured with noncontact tonometer). Intraocular pressure ranged from (18mm hg to $40 \mathrm{mmhg}$ ).In one patient IOP was un-recordable due to severe corneal edema and very high intraocular pressure.

$7^{\text {th }}$ Post operative day: None of the patients improved in form of visual acuity and corneal edema, but the anterior chamber inflammation reduced significantly due to use of topical steroids. Pupils were dilated and fixed and not reacting to light. Intraocular pressure was raised despite medical treatment for glaucoma in four out of 5 patients. All the patients (100\%) had diffuse pigment clumping at back of cornea adherent to corneal endothelium. Pigment clumps were also seen in the surgical site area in three out of five patients.(60\%)Few pigment clumps were also seen on surface of intraocular lens in all patients (FIGURE 3 AND 4).

At 6 weeks follow up (Table 2): The pigment clumps in cornea increased in all five patients associated with increasing corneal edema and corneal epithelial defects. Intraocular pressure was elevated despite medical treatment in four out of five patients. 
Pigment in the surgical wound area also increased considerably showing blackish discoloration in sclera in three out of five patients (2 phaco and one SICS). (FIGURE 5 AND 6) Visual acuity did not improve in any of the patient even with control of inflammation.

The reduction in visual acuity could be attributed to corneal edema and pigment clumping in central cornea obscuring the visual axis.

Four out of five patients lost to follow up after 6 weeks with one patient having regular follow up who despite aggressive treatment had subsequent corneal melting with secondary fungal keratitis, corneal perforation and pthisis bulbi.

DISCUSSION: TASS is a sterile post-operative inflammation of anterior segment surgery most commonly cataract surgery. All our patients had TASS as it occurred within 24 hours of surgery with Rim to Rim corned edema, corneal epithelial defects, severe reaction in anterior chamber, marked decreased vision and photophobia.

It was differentiated from endophthalmitis as red glow was preserved in all patients with clear vitreous cavity on fundus examination and Inflammation in anterior chamber responded to topical and systemic steroids.

The signs of inflammation occurred on the first post-operative day in contrast to endophthalmitis which usually develops after two to seven days and the patients symptoms were less when compared to the amount of inflammation in contrast to endophthalmitis.

TASS with severe pigment dispersion in anterior segment of eye is a rare complication and carries a poor prognosis, as it can lead to severe corneal decompensation, uncontrolled Intraocular pressure with severe visual dysfunction.

Other causes of severe pigment dispersion following cataract surgery include the implantation of posterior chamber intraocular lens in the Sulcus.

This may be due to chaffing of Iris pigments caused by IOL haptic touching the posterior pigment epithelium of iris and reduced distance between IOL and Iris pigment epithelium. ${ }^{[9,10]}$

In majority of patients with pigment dispersion placement of one of IOL haptics in sulcus was the major cause and they occur rarely even when both the haptics lie inside the capsular bag. [11,12,13]

The angle of inclination of IOL haptics, and implantation techniques can alter the Iris pigment epithelium and can cause pigment dispersion.[14]

The pigment dispersion caused by IOL usually occurs as a delayed complication in contrast to TASS in which the pigment dispersion occurred in the $2^{\text {nd }}$ post-operative week, as in our study. In our study all the IOL's were implanted inside the capsular bag.

The etiology of TASS is multi factorial which includes toxins from surgical equipment, Balanced Salt Solutions, debris from surgical equipment's, chemicals from enzymatic cleaners, antiseptics, talc from surgical gloves, denatured viscoelastics, use of intra cameral agents with preservatives and antibiotic ointment accessing into anterior chamber. All our cases occurred sporadically over a period of time. The etiology of TASS could not be clearly established in our cases.

By implementing certain modifications in operation theatre protocol such as switching over to non-powdered (talc free gloves) from powdered gloves, use of disposal Irrigation aspiration cannulas, use of preservative free epinephrine for Intra cameral use, changing to new batch and company of viscoelastics, greater emphasis of meticulous mechanical cleaning of surgical instruments, refraining use of antibiotic eye ointment immediately after surgery, and adequate 
washing of IOL's with Balanced Salt Solution before implantation, no new cases of severe TASS with pigment dispersion occurred although milder form of TASS do occur.

CONCLUSION: TASS with severe pigment dispersion is a rare entity. If occurs it is followed by severe complication to cornea and anterior chamber angle causing corneal decompensation and secondary glaucoma which persists even after the inflammation is brought under control. This may be due to the pigment clumps damaging the corneal endothelium and blocking the trabecular meshwork:

- In our study TASS with pigment dispersion occurred irrespective of the type of cataract surgery and intraocular lens used.

- Prevention of TASS is of primary importance as prevention of endophthalmitis

- While infections are the cause of endophthalmitis the etiology of TASS is predominantly toxins and chemicals.

- Simple modifications such as use of talc free gloves, proper cleaning of debris in surgical instruments, and phacotubings, use of non-enzymatic detergents for cleaning and use of preservative free intra cameral agents are necessary to prevent the occurrence of TASS.

\section{REFERENCES:}

1. Mamalis N, Edelhauser HF, DawsonDG, Toxic anterior segment syndrome. J Cataract refract surg. 2006: 32: $324-33$.

2. Cornut $\mathrm{pl}$, Vandenesch L et al. Bacterial contamination rate of the anterior chamber during cataract surgery using conventional culture and eubacterial PCR. Eur J Ophthalmol. 2010 MarApr; 20(2):365-9.

3. Ramanjit sihota parsons diseases of the eye, $20^{\text {th }}$ ed Endophthalmitis. Page 227-228

4. Holland Sp, Leetl update on toxic anterior segment syndrome. Curropthalmol 2007 Feb: 18 (1); $4-8$.

5. Caroles M, Cutter perk, Jacob Brubaker. Toxic anterior Segment Syndrome: Common causes Journal of Cataract of Refractive Surgery July 2010, Vol 36 (issue 7); 1073 - 1080.

6. Noor BakhtNizamani, Imranahmed cluster of UrretsZavalia Syndrome - a sequel of toxic anterior segment syndrome.Br J Ophthalmol 2013, 97: 976 - 979.

7. Zhao L, Lix R, Toxic Anterior Segment Syndrome ZhonghuayankeZaZhi 2008 Feb: 44(2) 180 4.

8. Gopal L, Vijaya L. Toxic ant Segment Syndrome.: Br. J opthalmol August 2013; 97(8).

9. Woodhams J, Lester JC, Pigment dispersion glaucoma secondary to post chamber IOL: Ann Opthalmol 1984, 16: $852-855$.

10. Maskets, Pseudophakic posterior Iris Chaffing syndrome. J cataract refract surg. 1998; 12: 252 $-256$.

11. Kohnean T, Kook D.Solving IOL related pigment dispersion syndrome without reposition of primary sulcus implanted single piece IOL in capsular bag J. Cataract ref. Surg: 2009; Aug; 35 (8); $1459-63$.

12. Samples JR, Van Bus kiskPigmentary of Glaucoma associated without post chamber intraocular lens; AMJ ophthalmol 1985; 100: 385 - 388.

13. Almond Mc, Chen PP. J. Cataract Refract surg. 2009, Dec. 35 (12): 2164.

14. Ballin N, Weiss DM. Pigment dispersion and Intraocular pressure elevation in pseudophakia. Ann ophthalmol 1982; 14; $627-630$. 


\begin{tabular}{|c|c|c|c|c|c|c|c|c|c|}
\hline PATIENT & $\begin{array}{l}\text { WOUND } \\
\text { PIGMENT } \\
\text {-ATION }\end{array}$ & $\begin{array}{c}\text { CORNEAL } \\
\text { EDEMA }\end{array}$ & $\begin{array}{c}\text { CORNEAL } \\
\text { ENDOTHELIAL } \\
\text { PIGMENT } \\
\text { CLUMPS }\end{array}$ & $\begin{array}{l}\text { PUPIL } \\
\text { SIZE }\end{array}$ & $\begin{array}{c}\text { RED } \\
\text { GLOW }\end{array}$ & IOP* & $\begin{array}{l}\text { TYPE OF } \\
\text { SURGERY }\end{array}$ & $\begin{array}{l}\text { TYPE OF } \\
\text { IOL }\end{array}$ & $\begin{array}{c}\text { VA* } \\
\text { WITH } \\
\text { PH* }\end{array}$ \\
\hline PATIENT I & ABSENT & $\begin{array}{l}\text { RIM TO RIM } \\
\text { WITH } \\
\text { EPITHELIAL } \\
\text { DEFECT }\end{array}$ & ABSENT & $\begin{array}{c}5 \mathrm{~mm} \\
\text { FIXED }\end{array}$ & PRESENT & $18 \mathrm{mmhg}$ & PHACO & $\begin{array}{c}\text { SINGLE } \\
\text { PIECE } \\
\text { HYDRO } \\
\text { PHILIC } \\
\text { IOL }\end{array}$ & $6 / 36$ \\
\hline $\begin{array}{l}\text { PATIENT } \\
\text { II }\end{array}$ & ABSENT & $\begin{array}{l}\text { RIM TO RIM } \\
\text { WITH } \\
\text { EPITHELIAL } \\
\text { DEFECT }\end{array}$ & ABSENT & $\begin{array}{c}7 \mathrm{~mm} \\
\text { FIXED }\end{array}$ & PRESENT & $34 \mathrm{mmhg}$ & PHACO & $\begin{array}{c}\text { THREE } \\
\text { PIECE } \\
\text { HYDRO } \\
\text { PHILIC } \\
\text { IOL }\end{array}$ & $3 / 60$ \\
\hline $\begin{array}{l}\text { PATIENT } \\
\text { III }\end{array}$ & ABSENT & $\begin{array}{l}\text { RIM TO RIM } \\
\text { WITH } \\
\text { EPITHELIAL } \\
\text { DEFECT }\end{array}$ & ABSENT & $\begin{array}{c}6 \mathrm{~mm} \\
\text { FIXED }\end{array}$ & PRESENT & $40 \mathrm{mmhg}$ & SICS & $\begin{array}{c}\text { PMMA } \\
\text { SINGLE } \\
\text { PIECE }\end{array}$ & $6 / 60$ \\
\hline $\begin{array}{l}\text { PATIENT } \\
\text { IV }\end{array}$ & ABSENT & $\begin{array}{l}\text { RIM TO RIM } \\
\text { WITH } \\
\text { EPITHELIAL } \\
\text { DEFECT }\end{array}$ & ABSENT & $\begin{array}{c}5 \mathrm{~mm} \\
\text { FIXED }\end{array}$ & PRESENT & $30 \mathrm{mmhg}$ & SICS & $\begin{array}{l}\text { PMMA } \\
\text { THREE } \\
\text { PIECE }\end{array}$ & $\mathrm{HM}$ \\
\hline $\begin{array}{c}\text { PATIENT } \\
\mathrm{V}\end{array}$ & ABSENT & $\begin{array}{l}\text { RIM TO RIM } \\
\text { WITH } \\
\text { EPITHELIAL } \\
\text { DEFECT }\end{array}$ & ABSENT & $\begin{array}{l}8 \mathrm{~mm} \\
\text { FIXED }\end{array}$ & PRESENT & $\begin{array}{c}\text { Not } \\
\text { recordable }\end{array}$ & SICS & $\begin{array}{l}\text { PMMA } \\
\text { THREE } \\
\text { PIECE }\end{array}$ & $\mathrm{PL}+$ \\
\hline
\end{tabular}

*VA - VISUAL ACUITY * PH - PIN HOLE *IOP - INTRAOCULAR PRESSURE

\begin{tabular}{|c|c|c|c|c|c|c|}
\hline PATIENT & $\begin{array}{c}\text { WOUND } \\
\text { PIGMENT } \\
\text {-ATION }\end{array}$ & $\begin{array}{l}\text { CORNEAL } \\
\text { EDEMA }\end{array}$ & $\begin{array}{c}\text { CORNEAL } \\
\text { ENDOTHELIAL } \\
\text { PIGMENT } \\
\text { CLUMPS }\end{array}$ & $\begin{array}{l}\text { PUPIL } \\
\text { SIZE }\end{array}$ & IOP & $\begin{array}{c}\text { VA } \\
\text { WITH } \\
\text { PH }\end{array}$ \\
\hline PATIENT I & PRESENT & $\begin{array}{c}\text { RIM TO RIM WITH } \\
\text { EPITHELIAL DEFECT }\end{array}$ & DIFFUSE & $\begin{array}{c}5 \mathrm{~mm} \\
\text { FIXED }\end{array}$ & $18 \mathrm{mmhg}$ & $6 / 60$ \\
\hline PATIENT II & PRESENT & $\begin{array}{c}\text { RIM TO RIM WITH } \\
\text { EPITHELIAL DEFECT }\end{array}$ & DIFFUSE & $\begin{array}{c}7 \mathrm{~mm} \\
\text { FIXED }\end{array}$ & $30 \mathrm{mmhg}$ & $3 / 60$ \\
\hline PATIENT III & NIL & $\begin{array}{l}\text { RIM TO RIM WITH } \\
\text { EPITHELIAL DEFECT }\end{array}$ & DIFFUSE & $\begin{array}{l}6 \mathrm{~mm} \\
\text { FIXED }\end{array}$ & 28mmhg & $5 / 60$ \\
\hline PATIENT IV & PRESENT & $\begin{array}{c}\text { RIM TO RIM WITH } \\
\text { EPITHELIAL DEFECT }\end{array}$ & DIFFUSE & $\begin{array}{c}\mathrm{mm} \\
\text { FIXED }\end{array}$ & $34 \mathrm{mmhg}$ & $\mathrm{HM}$ \\
\hline PATIENT V & NIL & $\begin{array}{l}\text { RIM TO RIM WITH } \\
\text { EPITHELIAL DEFECT }\end{array}$ & DIFFUSE & $\begin{array}{l}8 \mathrm{~mm} \\
\text { FIXED }\end{array}$ & $\begin{array}{l}\text { Not recordable } \\
\text { Digitally high }\end{array}$ & $\mathrm{PL}+$ \\
\hline
\end{tabular}

*VA - VISUAL ACUITY * PH - PIN HOLE *IOP - INTRAOCULAR PRESSURE 


\section{ORIGINAL ARTICLE}

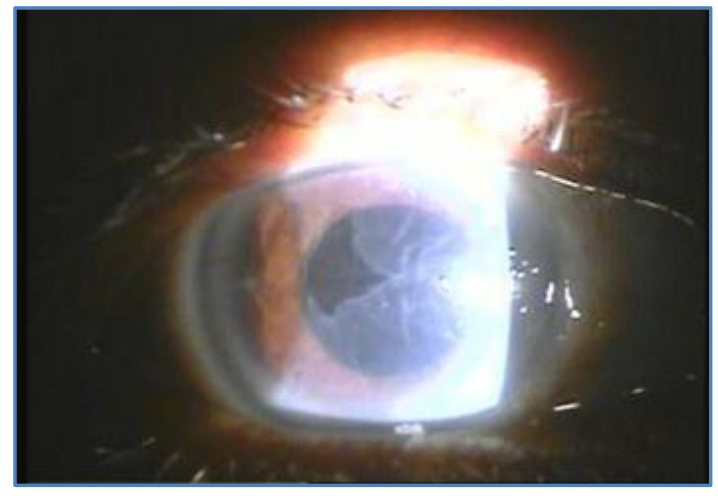

Fig. 1: Showing coreneal epithelial defect

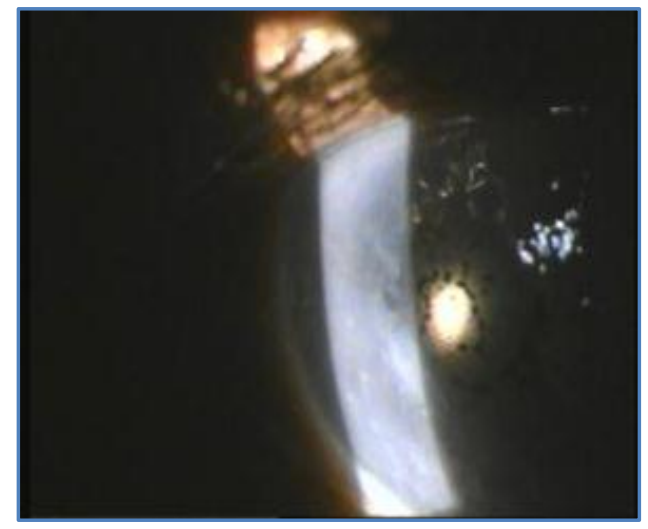

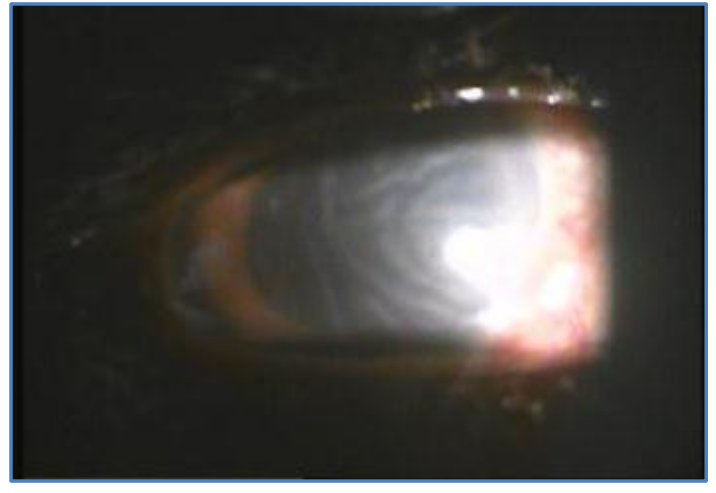

Fig. 2: Showing fixed dilated pupil

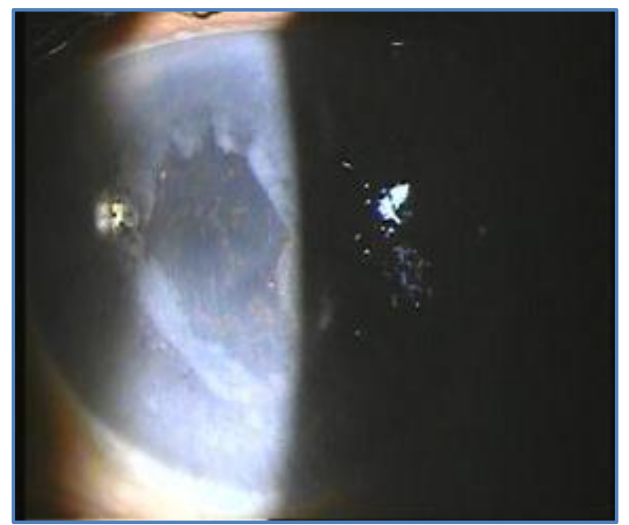

Fig. 3: \& 4: Showing pigment clumping in corneal endothelium

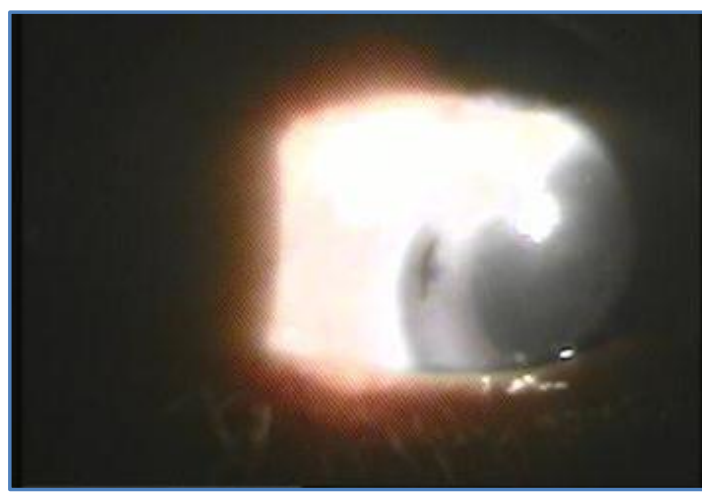

Fig. 5: Showing pigment from side port

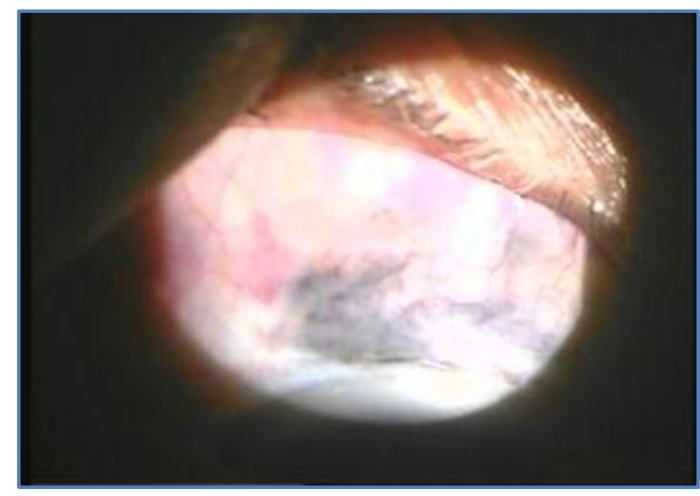

Fig. 6: Showing pigment in the surgical wound area with blackish discoloration in sclera 


\section{ORIGINAL ARTICLE}

\section{AUTHORS:}

1. K. Stephen Sudhakar

2. M. Loganathan

3. R. Panduragan

4. C. Charanya

\section{PARTICULARS OF CONTRIBUTORS:}

1. Associate Professor, Department of Ophthalmology, Chettinad Hospital and Research Institute.

2. Associate Professor, Department of Ophthalmology, Venkateshwara Medical College, Pondicherry.

3. Professor and HOD, Department of Ophthalmology, Chettinad Hospital and Research Institute.
4. Post Graduate, Department of Ophthalmology, Chettinad Hospital and Research Institute.

\section{NAME ADDRESS EMAIL ID OF THE CORRESPONDING AUTHOR:}

Dr. C. Charanya,

Urbanville Apartments,

Velachery Main Road,

Velachery, Chennai-600042.

Email: charanyachendilnathan@gmail.com

Date of Submission: 04/09/2014. Date of Peer Review: 05/09/2014.

Date of Acceptance: 15/09/2014.

Date of Publishing: 20/09/2014. 